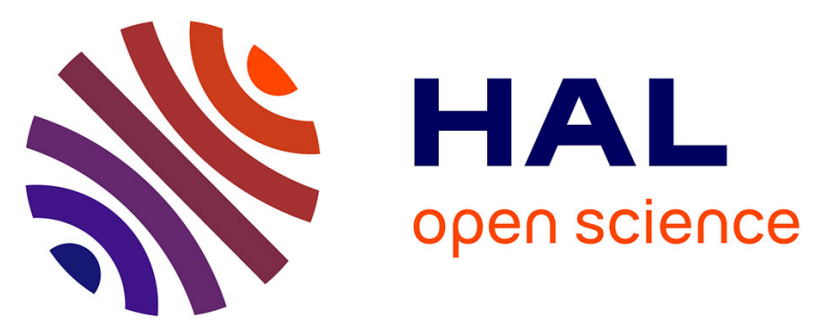

\title{
Influence of patient axial malpositioning on the trueness and precision of pelvic parameters obtained from 3D reconstructions based on biplanar radiographs
}

Bachir Ghostine, Christophe Sauret, Ayman Assi, Ziad Bakouny, Nour Khalil, Wafa Skalli, Ismat Ghanem

\section{To cite this version:}

Bachir Ghostine, Christophe Sauret, Ayman Assi, Ziad Bakouny, Nour Khalil, et al.. Influence of patient axial malpositioning on the trueness and precision of pelvic parameters obtained from 3D reconstructions based on biplanar radiographs. European Radiology, 2016, 27 (3), pp.1295-1302. 10.1007/s00330-016-4452-x . hal-02197220

\section{HAL Id: hal-02197220 \\ https://hal.science/hal-02197220}

Submitted on 30 Jul 2019

HAL is a multi-disciplinary open access archive for the deposit and dissemination of scientific research documents, whether they are published or not. The documents may come from teaching and research institutions in France or abroad, or from public or private research centers.
L'archive ouverte pluridisciplinaire HAL, est destinée au dépôt et à la diffusion de documents scientifiques de niveau recherche, publiés ou non, émanant des établissements d'enseignement et de recherche français ou étrangers, des laboratoires publics ou privés. 


\title{
Influence of patient axial malpositioning on the trueness and precision of pelvic parameters obtained from 3D reconstructions based on biplanar radiographs
}

\author{
Bachir Ghostine ${ }^{1,2} \cdot$ Christophe Sauret $^{1} \cdot$ Ayman Assi $^{1,2} \cdot$ Ziad Bakouny $^{2} \cdot$ \\ Nour Khalii $^{2} \cdot$ Wafa Skalli ${ }^{1} \cdot$ Ismat Ghanem $^{2,3}$
}

\begin{abstract}
Objectives Radiographs are often performed to assess pelvic and hip parameters, but results depend upon correct pelvis positioning. Three-dimensional (3D) reconstruction from biplanar-radiographs should provide parameters that are less sensitive to pelvic orientation, but this remained to be evaluated.

Methods Computerized-tomographic scans of six patients were used both as a reference and for generating simulated frontal and lateral radiographs. These simulated radiographs were generated while introducing axial rotations of the pelvis ranging from $0^{\circ}$ to $20^{\circ}$. Simulated biplanar-radiographs were utilized by four operators, three times each, to perform pelvic 3D-reconstructions. These reconstructions were used to assess the trueness, precision and global uncertainty of radiological pelvic and hip parameters for each position.

Results In the neutral position, global uncertainty ranged between $\pm 2^{\circ}$ for pelvic tilt and $\pm 9^{\circ}$ for acetabular posterior sector angle and was mainly related to precision errors (ranging from $1.5^{\circ}$ to $7^{\circ}$ ). With increasing axial rotation, global uncertainty increased and ranged between $\pm 5^{\circ}$ for pelvic tilt and $\pm 11^{\circ}$ for pelvic incidence, sacral slope and acetabular anterior sector angle, mainly due to precision errors.
\end{abstract}

Conclusion Radiological parameters obtained from 3D-reconstructions, based on biplanar-radiographs, are less sensitive to axial rotation compared to plain radiographs. However, the axial rotation should nonetheless not exceed $10^{\circ}$.

Key points

- Pelvic radiological parameters could be affected by patient malpositioning.

- Biplanar radiograph-based 3D reconstructions were performed at increments of axial rotation.

- Trueness, precision and global uncertainty were evaluated for pelvic and hip radiological parameters.

- Hip parameters were less affected by rotation compared to pelvic parameters.

- Maintaining the pelvis close to the neutral position is recommended to ensure the highest possible accuracy.

Keywords Pelvis · Rotation · Biplanar X-rays · Trueness · Precision

\section{Introduction}

Coronal and sagittal pelvic radiographs are often carried out for the assessment of hip disorders. However, interpretation is difficult because the projected morphological features of the acetabulum, and almost all radiological parameters of the hip, depend on the position of the pelvis [1-6], which can vary considerably between acquisitions. Because this assessment will substantially influence diagnosis and treatment, more accurate analysis of the morphologic features of the acetabulum is essential. This has led to a growing interest in threedimensional (3D) imaging of the pelvis with computerized tomographic scans (CT-scan) [1]. Three-dimensional CT-scan analysis provides accurate local diagnoses and allows surgical planning in the setting of pathologies such as congenital hip 
dysplasia and impingement syndrome. Furthermore, it can be used to understand the mechanisms of hip dislocations after total hip arthroplasty. However, CT-scans expose patients to high doses of radiation. In addition, since CT-scans are performed in a supine position, standing positional parameters such as pelvic tilt and sacral slope cannot be adequately assessed. Low-dose biplanar radiographs could be an interesting alternative [7-9], since they allow low dose acquisition in the standing position, with 3D reconstruction of multiple skeletal segments. The methods of $3 \mathrm{D}$ reconstruction using biplanar radiographs have been previously validated for the spine [10], lower limbs [11-13] and proximal femur [14].

Despite the reported advantages of this system, it is often difficult to control the exact position of the patient during the acquisition in daily practice. Pelvis rotations (axial, tilt and obliquity) could affect the visibility, on the frontal and sagittal radiographs, of some of the anatomical landmarks of the pelvis used for 3D reconstructions, potentially leading to reconstruction errors. Therefore, the accuracy of the radiological parameters defined from 3D pelvic reconstruction could be affected, with possible negative implications on the diagnosis and treatment of hip pathologies.

The effects of patient axial malpositioning on twodimensional (2D) pelvic parameters have already been assessed on cadavers [1-3]. However, to our knowledge, the only study that had reported its effects on 3D radiological parameters [9] was based on a single dry cadaveric pelvis (without the surrounding soft tissues) and did not focus on the effects of axial rotation on the $3 \mathrm{D}$ radiological parameters.

A study of the effect of patient malpositioning, during biplanar radiograph acquisition, would necessitate repeated pairs of frontal and lateral radiographs of the same subjects at different axial rotation positions. This would not be ethically feasible, considering the unnecessary radiation dose to which these subjects would be exposed. Otherwise, a large number of cadaveric pelvises would be difficult to obtain. However, digital reconstruction of lateral and frontal radiographs from 3D pelvic CT-scans, in the calibrated low dose biplanar radiographs environment [15-17], could overcome the aforementioned obstacles. Indeed, this innovative numerical technique allows the simulation of a change in the direction of the X-ray source, thus generating an unlimited number of lateral and frontal virtual radiographs, at different increments of axial rotation, from the same CT-scan images.

The aim of this study was to evaluate the influence of pelvis axial rotation on both trueness and precision of the most clinically relevant pelvic and hip parameters obtained from 3D reconstructions, based on low dose biplanar radiographs and the associated reconstruction methods.

\section{Material and methods}

\section{Population}

Helical pelvic CT-scans of six patients (slice thickness: $0.6 \mathrm{~mm}$, resolution: $512 \times 512$, pixel spacing: $0.7675 \mathrm{~mm}$ ) were extracted from the database of the radiology department of our university hospital. All six patients had undergone CTscans to investigate abdominal disorders and none had orthopedic complaints. Patients had an average age of 48.1 \pm 29.1 years, ranging from 15 to 80 years, and were equally distributed between both genders. Patients undergoing clinical exams at our university hospital are systematically asked to sign an authorization that allows the use of their anonymous data for research purposes. The design of the present study was approved by the institutional review board of our university.

\section{Pelvis 3D reconstructions}

CT-scans were used for two different purposes. First, the CT-scan images were used to create a $3 \mathrm{D}$ reconstruction of the pelvis. This 3D reconstruction was used to determine the values of the pelvis and hip radiological parameters that were considered as the references. Second, the same CT-scan images were used to generate pairs of virtual radiographs, in the calibrated low dose biplanar radiographs environment [15-17], while introducing axial rotation of the CT volume from $0^{\circ}$ to $20^{\circ}$, in $5^{\circ}$ increments. This allowed the generation of five pairs of virtual radiograph (at $0^{\circ}, 5^{\circ}, 10^{\circ}, 15^{\circ}$ and $20^{\circ}$ of axial rotation) for each patient. These pairs of virtual radiographs were then processed using previously described techniques to obtain the 3D reconstruction of the pelvis $[7,11,12,18,19]$ in each selected axial rotation position. Briefly, the 3D reconstruction technique of the pelvis is based on the detection of anatomical landmarks of the pelvis and proximal femur, on both the lateral and frontal radiographs, such as sacral plate contour, sacro-iliac joint, acetabular rims, anteriorsuperior iliac spine, pubic symphysis, greater trochanter, femoral neck and femoral condyles (Fig. 1a). This allows a first estimation of the 3D pelvis shape that can be retroprojected on both images. The model is then adjusted by modifying the pelvic contours on both frontal and lateral radiographs for a best fit between retro-projected and radiographic contours (Fig. 1b).

\section{Measured parameters}

From the subject-specific 3D reconstructions based on biplanar radiographs, pelvic and hip radiological parameters were automatically calculated (Fig. 1c). The considered positional parameters were pelvic tilt (PT), sacral slope (SS) and 
Fig. 1 Process of the 3D reconstruction of the Pelvis: $a$ ) selection of anatomical landmarks, $b$ ) adjustment of the 3D model, c) calculation of 3D radiological parameters, $d$ ) example of $3 \mathrm{D}$ reconstruction of the pelvis
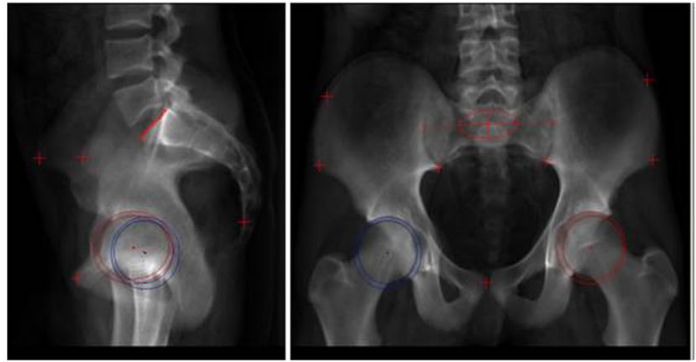

a

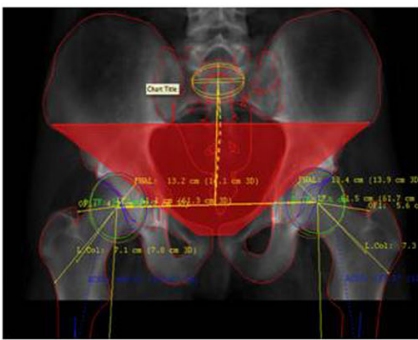

C

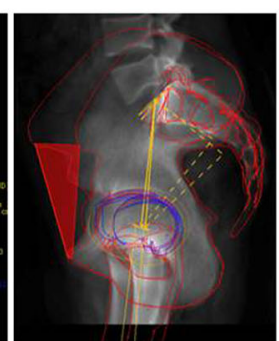

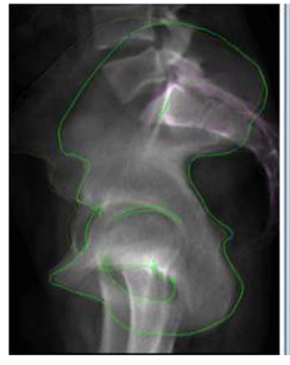

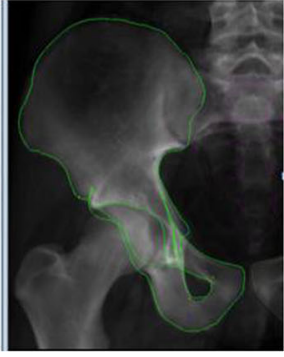

b

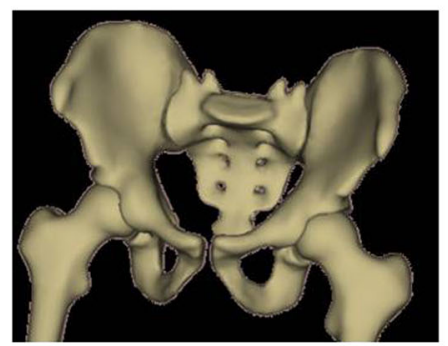

d pelvic incidence (PI) [19-25]. The considered acetabular parameters were: the center-edge angle (CEA), which indicates the superior coverage of the femoral head [26]; the acetabular coverage (AC), which represents the ratio of femoral head surface covered by the acetabulum [8]; the acetabular inclination (AI), which represents the inclination of the plane of the acetabular edge [8] with respect to a vertical axis; the acetabular anteversion (AA), which represents the orientation of the plane of the acetabular edge with respect to the postero-anterior axis of the pelvis [27-29]; the Idelberg and Frank angle (IFA), which indicates the acetabular depth [30,31]; the acetabular anterior sector angle (AASA) and the acetabular posterior sector angle (APSA), which reflect the coverage of the femoral head by the acetabulum anteriorly and posteriorly, respectively [27]. All these parameters are illustrated in Fig. 2.

\section{Data analysis and statistical method}

Four independent qualified operators (different from the person who generated the virtual radiographs) performed the 3D pelvic reconstructions using the biplanar radiographs. Each operator reconstructed all six patients, in all of the axial rotation positions (Figs. 2 and 3), in a random order. The reconstruction from each pair of virtual radiographs was repeated three times by each operator with 1 -week intervals. Thus, 12 biplanar radiographs 3D reconstructions were available for each patient at each axial rotation position.

For each radiological parameter, trueness and precision were evaluated for all patients, in each axial rotation position. The reference value for each radiological parameter was obtained from the CT-scan 3D reconstruction as mentioned above. Bland-Altman plots [32] were generated for all parameters to investigate possible significant differences between operators.

In agreement with metrology standards [33, 34], two elements were quantified: trueness and precision. Trueness, also reported as validity, is defined as the agreement between the average of repeated measurements and the reference and represents a systematic error, which quantifies the measurement bias $(\delta)$ [33]. Precision, also reported as reliability, is defined as a random error that represents the agreement of the results obtained by replicate measurements by multiple operators. This error is often assessed by calculating the intraclass correlation coefficient (ICC). In this study, the ICC $(2, \mathrm{k})$ model was calculated for each parameter, at each axial rotation position, on the whole data set. However, ICC does not provide results directly related to the quantified uncertainty of measurement (angles in degrees, distances in $\mathrm{mm}$ ). For this reason, precision was also assessed according to the guidelines of ISO 5725-2 standard [34] through the reproducibility standard deviation $\left(S_{R}\right)$, which involves both the intra- and inter-observer variances.

The global uncertainty $( \pm \varepsilon)$ on the result of a measurement includes both the systematic (trueness) and random (precision) errors. It was calculated as the sum of the bias $(\delta)$ and the $95 \%$ confidence interval $\left(C I_{95 \%}\right)$. In this study, we chose to express global uncertainty in its most "unfavorable" definition (the one that results in the highest absolute error), using the absolute value of the bias and $2 \mathrm{~S}_{\mathrm{R}}$ for the $95 \%$ confidence interval: 

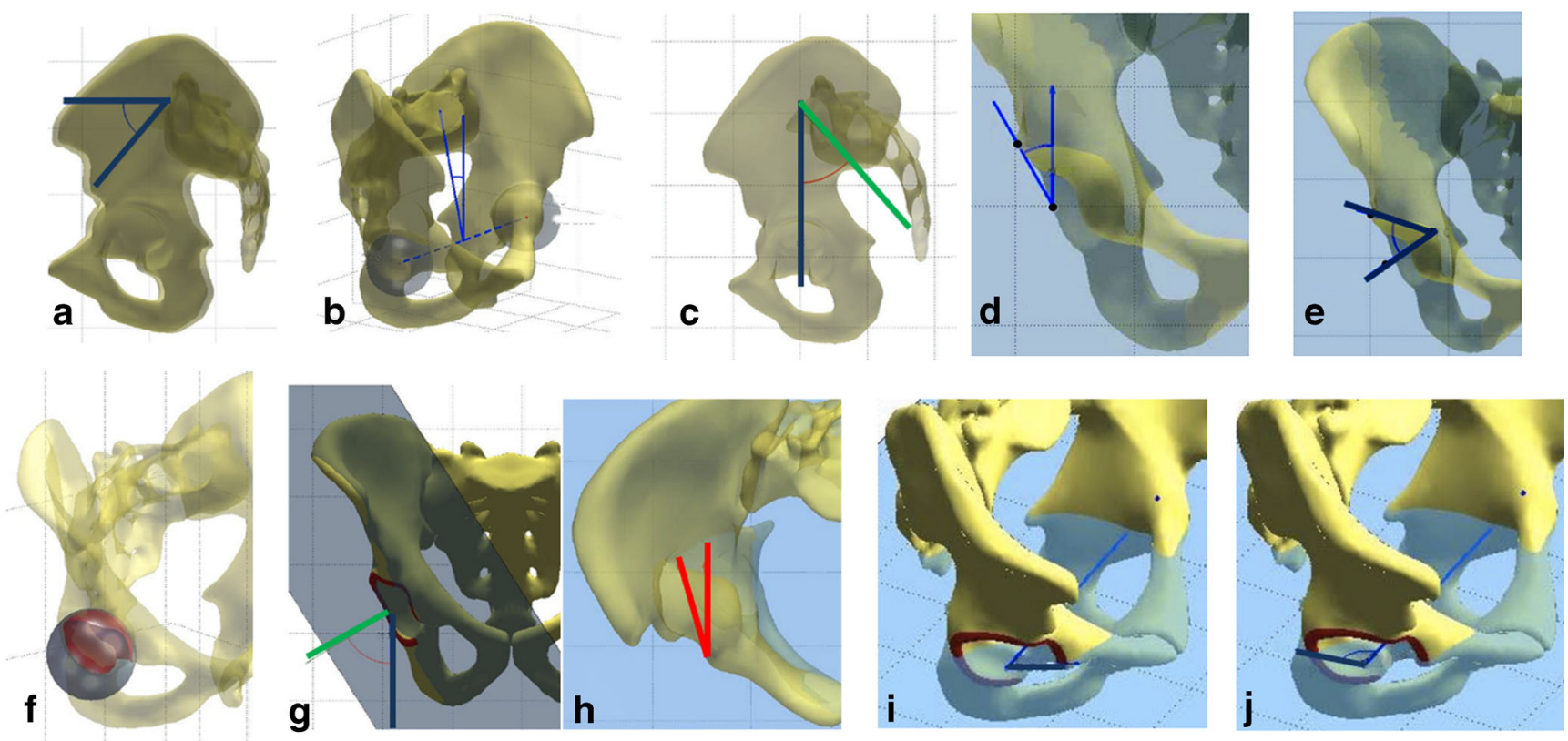

Fig. 2 Representation of the different radiological parameters calculated on the 3D pelvis reconstruction: $a$ ) sacral slope, $b$ ) pelvic tilt, $c$ ) pelvic incidence, $d$ ) center-edge angle, $e$ ) Idelberg-Frank angle, $f$ ) acetabular

$\varepsilon=|\delta|+2 \mathrm{~S}_{\mathrm{R}}$

\section{Results}

\section{In the neutral axial rotation position}

Results for bias $(\delta)$, reproducibility standard deviation $\left(S_{R}\right)$ and global uncertainty $(\varepsilon)$ in the neutral position $\left(0^{\circ}\right.$ of axial rotation) for each radiological parameter are summarized in Table 1. Pelvic tilt exhibited both the lowest bias $\left(\delta=0.1^{\circ}\right)$ and coverage of the femoral head, $g$ ) acetabular inclination, $h$ ) acetabular anteversion, $i$ ) acetabular anterior sector angle (AASA), $j$ ) and acetabular posterior sector angle

reproducibility standard deviation $\left(S_{R}=0.75^{\circ}\right)$ providing a global uncertainty $(\varepsilon)$ under $2^{\circ}$. For most of the parameters, bias was contained between $0.5^{\circ}$ and $1.5^{\circ}$, and the reproducibility standard deviation between $1.5^{\circ}$ and $2.5^{\circ}$. For Acetabular coverage, which was the only parameter expressed in percentage, bias was about $1 \%$ and the reproducibility standard deviation was about $2 \%$. The highest bias was found for Acetabular posterior sector angle $\left(\delta=-2.9^{\circ}\right)$ and the highest reproducibility standard deviation for the Acetabular anterior sector angle $\left(S_{R}=3.4^{\circ}\right)$.

Consequently, many of the studied parameters showed a global uncertainty ranging from $5^{\circ}$ to $6^{\circ}$ except for Centeredge angle, Acetabular anterior sector angle and Acetabular
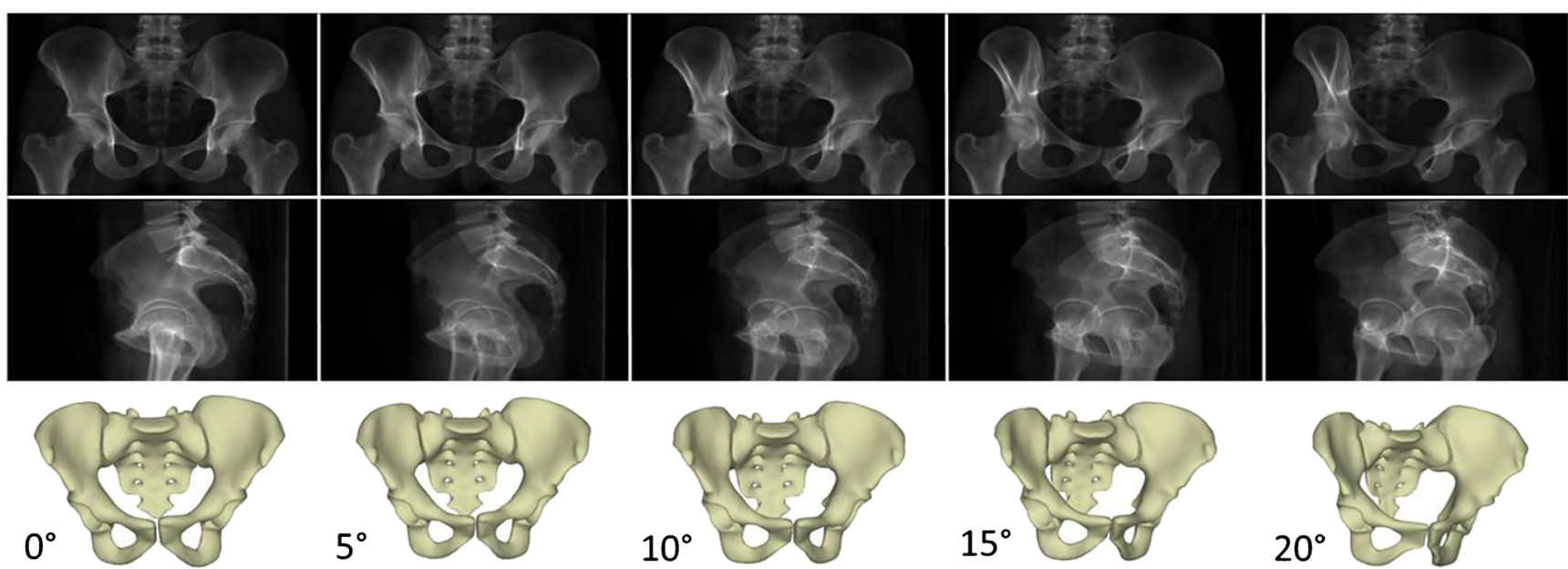

Fig. 3 Frontal and lateral digitally reconstructed radiographs of the pelvis at different increments of axial rotation positions with their corresponding 3D reconstructions 
Table 1 Bias $(\delta)$, reproducibility standard deviation $\left(S_{R}\right)$, global uncertainty $\left(\varepsilon=|\delta|+2 S_{R}\right)$ and intraclass correlation coefficient (ICC) for the different pelvic and hip parameters in neutral axial rotation position

\begin{tabular}{lllll} 
& Bias $(\delta)$ & Reproducibility $\left(S_{R}\right)$ & Global uncertainty $(\varepsilon)$ & ICC \\
\hline Pelvic tilt $\left({ }^{\circ}\right)$ & 0.1 & 0.8 & 2 & 0.99 \\
Sacral slope $\left(^{\circ}\right)$ & 0.5 & 2.5 & 6 & 0.98 \\
Pelvic incidence $\left({ }^{\circ}\right)$ & -0.1 & 2.7 & 6 & 0.99 \\
Idelberg-Frank $\left({ }^{\circ}\right)$ & 1.2 & 1.7 & 5 & 0.94 \\
Acetabular coverage $(\%)$ & 1.0 & 1.9 & 5 & 0.99 \\
Inclination $(A I)\left({ }^{\circ}\right)$ & 1.4 & 1.8 & 5 & 0.98 \\
Anteversion $(A T)\left({ }^{\circ}\right)$ & 0.4 & 2.3 & 5 & 0.98 \\
CEA $\left({ }^{\circ}\right)$ & -1.6 & 2.9 & 8 & 0.99 \\
AACA $\left(^{\circ}\right)$ & -0.8 & 3.4 & 8 & 0.82 \\
APCA $\left({ }^{\circ}\right)$ & -2.9 & 2.9 & 9 & 0.98 \\
\hline
\end{tabular}

posterior sector angle, where it ranged between $8^{\circ}$ and $9^{\circ}$. While Pelvic tilt showed the lowest global uncertainty $\left(\varepsilon<2^{\circ}\right)$, Acetabular posterior sector angle showed the highest one $\left(\varepsilon=9^{\circ}\right)$.

The intraclass correlation coefficients (ICC) were higher than 0.98 for all parameters, except for Acetabular anterior sector angle, for which the ICC was 0.82 .

\section{In the presence of axial rotation}

For almost all parameters, the biases (calculated with respect to the CT-scan reference values and not to the average value in the neutral position) were not altered by axial rotation of the pelvis (Table 2). Biases increased only for Center-edge angle and Pelvic tilt, but this increase remained under $1^{\circ}$. The reproducibility standard deviation increased for all parameters with increasing axial rotation, except for Acetabular coverage, where it remained constant (Table 3). However, the increase in reproducibility standard deviation remained under $1.5^{\circ}$, except for Sacral slope and Pelvic incidence where the increase was higher (about $2.5^{\circ}$ ).

Consequently, the global uncertainty $(\varepsilon)$ increased with axial rotation. It was higher than $5^{\circ}$ for all parameters when axial rotation of the pelvis reached $20^{\circ}$. The parameters that were least affected by axial rotation were Idelberg and Frank angle, Acetabular coverage, Acetabular inclination and Acetabular anteversion with a global uncertainty of $6^{\circ}$ (or $6 \%$ ) for all axial rotations. Sacral slope and Pelvic incidence were the most affected by axial rotation.

The ICC decreased with increasing axial rotation for all parameters. However, ICC remained generally higher than 0.95 . The Acetabular anterior sector angle at $20^{\circ}$ of axial rotation had the lowest ICC $(0.78)$.

\section{Discussion}

The aim of the present study was to evaluate the effect of pelvis axial rotation (from $0^{\circ}$ to $20^{\circ}$ ) on both trueness and precision of 3D pelvic and hip radiological parameters obtained from biplanar radiographs $3 \mathrm{D}$ reconstructions. For this purpose, four operators reconstructed the pelvises of six patients, three times each, in different axial rotation positions, in a random order. While the bias increased only marginally with the increase in pelvis axial rotation, the reproducibility standard deviation, and consequently the global uncertainty, increased substantially.

Few studies have evaluated the effect of axial rotation of the pelvis on the accuracy of radiological parameters [35]. However, the comparison of our results to the literature is difficult because the studied parameters had been calculated in 2D. Moreover, the assessment of uncertainty had been performed using a different method. In the current study, we have chosen to apply the guidelines of the ISO standards in order to evaluate the trueness and precision of the radiological parameters $[33,34]$.

The results of our study have shown that the precision error of positional and morphological parameters in the neutral position (at $0^{\circ}$ of axial rotation) was generally lower than $2.5^{\circ}$ or $2.5 \%$, which is in accordance with previous studies using two-dimensional radiographs [36, 37]. These errors are, however, slightly higher for certain parameters such as Sacral

Table 2 Bias $(\delta)$ of pelvic and hip parameters at different degrees of axial rotation

\begin{tabular}{lrrrrr}
\hline & $0^{\circ}$ & $5^{\circ}$ & $10^{\circ}$ & $15^{\circ}$ & $20^{\circ}$ \\
\hline Pelvic tilt $\left(^{\circ}\right)$ & 0.1 & 0.4 & 0.8 & 1.2 & 1.3 \\
Sacral slope $\left(^{\circ}\right)$ & 0.5 & 0.6 & 0.6 & -0.5 & 0.6 \\
Pelvic incidence $\left(^{\circ}\right)$ & -0.1 & -0.2 & 0.0 & 1.3 & 0.2 \\
Idelberg-Frank $\left({ }^{\circ}\right)$ & 1.2 & 1.6 & 1.8 & 1.8 & 1.8 \\
Acetabular coverage $(\%)$ & 1.0 & 1.1 & 0.7 & 1.1 & 0.8 \\
Inclination $\left({ }^{\circ}\right)$ & 1.4 & 1.4 & 1.2 & 1.4 & 1.5 \\
Anteversion $\left({ }^{\circ}\right)$ & 0.4 & 0.5 & 0.0 & 0.2 & 0.0 \\
CEA $\left({ }^{\circ}\right)$ & -1.6 & -1.8 & -2.0 & -1.9 & -2.5 \\
AACA $\left({ }^{\circ}\right)$ & -0.8 & -1.1 & -0.9 & -1.2 & -1.5 \\
APCA $\left({ }^{\circ}\right)$ & -2.9 & -2.7 & -3.2 & -3.1 & -3.0
\end{tabular}


Table 3 Reproducibility standard deviation $\left(S_{R}\right)$ and interobserver ICC agreement of pelvis and hip parameters for different degrees of axial rotation

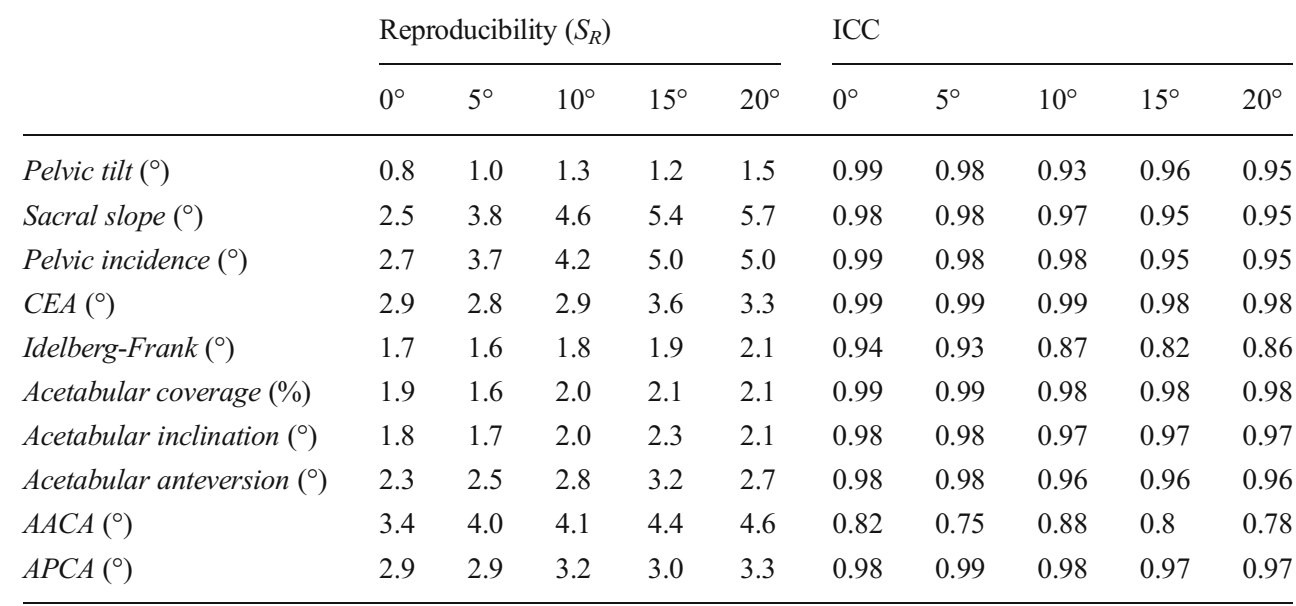

slope, Pelvic incidence $\left(S_{R} \approx 1.5^{\circ}\right)[10,38]$ and Acetabular inclination $\left(S_{R} \approx 0.8^{\circ}\right)$ [18], when compared to previous studies using biplanar radiograph-based $3 \mathrm{D}$ reconstructions. The methodology (number of operators, number of reconstructions, and calculation modality) and the use of virtual radiographs instead of real biplanar radiographs could be the reasons behind these differences. The precisions of Pelvic tilt and Pelvic incidence were similar to those reported in the literature $\left(S_{R} \approx 1^{\circ}\right.$ and $S_{R} \approx 2.5^{\circ}$, respectively) [10, 18, 38].

To our knowledge, the evaluation of the trueness (bias) of $3 \mathrm{D}$ reconstructions of the pelvis has not been previously reported in the literature.

In the presence of pelvic axial rotation, global uncertainty was altered for all parameters, and this was also mostly due to precision error rather than bias. The pelvic parameters (Pelvic incidence, Sacral slope and Pelvic tilt) were the most affected by the introduction of axial rotation, mainly due to the difficulty to detect the sacral plate on the lateral radiograph with increasing rotation, where the superposition of the iliac wings over the sacral plate rendered its visibility difficult. Hip parameters were less affected and maintained a global uncertainty close to $5^{\circ}$ (or $5 \%$ ), even in the presence of increasing axial rotation. This can be explained by the fact that, during the $3 \mathrm{D}$ reconstruction process, hip anatomical landmarks were detected on both anteroposterior and lateral images, and this detection was rarely affected by axial rotation. Furthermore, the two hips, which had been superimposed in the neutral position, became more distant from each other with increasing degrees of axial rotation; this in turn facilitated the detection of anatomical landmarks by reducing the overlap between the two hips.

Our results have shown greater accuracy (less global uncertainty) compared to those of previous studies performed on 2D radiographs [5] and 2D CT-scans [39]. However, we noticed that the global uncertainty of most parameters sharply increased when axial rotation exceeded $10^{\circ}$.
Multiple studies have previously used the intraclass correlation coefficient to express the precision of $2 \mathrm{D}$ parameters. Its value had been generally found to be between 0.50 and 0.99 , depending on the parameter and on the level of pelvic tilt and/or axial rotation $[2,6,9$, 39-42]. In this study, ICCs in the neutral position were found to be higher than those of 2D parameters and close to those reported in the only previous study based on biplanar radiographs. However, several authors have underlined the ICC's limitations [32, 43]. In our study, the ICC was not always related to the reproducibility standard deviation $\left(S_{R}\right)$, i.e., some parameters exhibited higher ICC than other parameters while exhibiting higher $S_{R}$ (Center-edge angle vs Idelberg and Frank angle in the neutral position, for instance). In addition, while the precision of many parameters was altered by increasing axial rotation of the pelvis, the ICC remained very high $(\geq 0.95$ for most parameters). For this reason, we preferred to report the global uncertainty on each parameter along with the ICC value.

This study was made possible through the use of digitally reconstructed radiographs, generated from original CT-scan images. Although the use of virtual radiographs instead of real radiographs can be seen as a limitation, this study could not have been done with real radiographs due to the high dose of radiation to which subjects would have been unnecessarily exposed. Moreover, the CT-scans that were used for radiograph generation were obtained on living subjects and therefore included surrounding soft tissues, which allowed the simulation of realistic gray levels on the radiographs. Unfortunately, information about patients and axial rotation levels were not unknown to the operators when they performed the $3 \mathrm{D}$ reconstructions. However, the number of reconstructions that need to be performed randomly (30 pairs of radiographs) would limit the impact of this bias on the presented results. In addition, the four operators were blinded of their results 
until the end of the study. The number of patients included in this study (i.e., six patients), even if relatively large for this kind of study, can also be seen as a limitation. Expanding the number of subjects would increase the statistical power of the results, but would probably not affect the conclusions of the study. Finally, although this study focused only on pelvis axial rotation, the authors acknowledge that pelvic tilt and obliquity (and any combination of axial rotation, tilt and obliquity) could also affect the accuracy of pelvis and hip radiological parameters.

Potential limitations for the use of low dose biplanar radiographs in routine clinical practice are the necessity of a well-trained operator and the time required to perform the $3 \mathrm{D}$ reconstructions. Careful and accurate identification of anatomical landmarks during the steps of reconstruction are very important in order to maintain good accuracy for all parameters. Thus, for a trained operator, a thorough pelvis $3 \mathrm{D}$ reconstruction could take up to 30 minutes, although the necessary time for reconstruction becomes shorter with increased operator experience and the potential increase of automation with further software improvement. Furthermore, the time required for biplanar radiograph-based $3 \mathrm{D}$ reconstruction remains inferior to that required for an accurate pelvis $3 \mathrm{D}$ reconstruction from the segmentation of a full set of CT-scan images. Moreover, current studies focusing on the reduction of the radiation dose (from low-dose to micro-dose) are encouraging [44]. This will allow more regular patient examination for follow-up.

In conclusion, while $3 \mathrm{D}$ reconstruction decreases the uncertainties of pelvic radiological parameters and could minimize the effect of patient malpositioning during biplanar radiograph acquisition, it is recommended to maintain the pelvis close to the neutral position.

Acknowledgements The scientific guarantor of this publication is Ismat Ghanem.

The authors of this manuscript declare no relationships with any companies, whose products or services may be related to the subject matter of the article. Wafa Skalli is coinventor of the EOS low dose bi-planar X-Ray system, without personal financial benefit.

This study has received funding by the research council of the University of Saint-Joseph (grant number FM276) and the FrenchLebanese cooperation for research CEDRE (grant number 11 SCI F 44/L36). The sponsors had no involvement in study design; in the collection, analysis and interpretation of data; in the writing of the report; and in the decision to submit the article for publication. No complex statistical methods were necessary for this paper. Institutional Review Board approval was obtained.

Written informed consent was not required for this study because data were previously obtained for clinical purpose and subject gave their informed consent for their further use in research purposes. Methodology: retrospective, observational, performed at one institution.

\section{References}

1. Jacobsen S, Sonne-Holm S, Lund B, Söballe K, Kiaer T, Rovsing H et al (2004) Pelvic orientation and assessment of hip dysplasia in adults. Acta Orthop Scand 75:721-729

2. Tannast M, Zheng G, Anderegg C, Burckhardt K, Langlotz F, Ganz $R$ et al (2005) Tilt and rotation correction of acetabular version on pelvic radiographs. Clin Orthop Relat Res 438:182-190

3. Weinert DJ (2005) Influence of axial rotation on chiropractic pelvic radiographic analysis. J Manip Physiol Ther 28:117-121

4. Clohisy JC, Carlisle JC, Trousdale R, Kim YJ, Beaule PE, Morgan $P$ et al (2009) Radiographic evaluation of the hip has limited reliability. Clin Orthop Relat Res 467:666-675

5. van der Bom MJ, Groote ME, Vincken KL, Beek FJ, Bartels LW (2011) Pelvic rotation and tilt can cause misinterpretation of the acetabular index measured on radiographs. Clin Orthop Relat Res 469:1743-1749

6. Dandachli W, U1 Islam S, Richards R, Hall-Craggs M, Witt J (2013) The influence of pelvic tilt on acetabular orientation and cover: a three-dimensional computerised tomography analysis. Hip Int 23:87-92

7. Mitton $\mathrm{D}$, Deschènes $\mathrm{S}$, Laporte $\mathrm{S}$, Godbout $\mathrm{B}$, Bertrand $\mathrm{S}$, de Guise JA et al (2006) 3D reconstruction of the pelvis from biplanar radiography. Comput Methods Biomech Biomed Engin 9: $1-5$

8. Humbert L, Carlioz H, Baudoin A, Skalli W, Mitton D (2008) 3D Evaluation of the acetabular coverage assessed by biplanar X-rays or single anteroposterior X-ray compared with CT-scan. Comput Methods Biomech Biomed Engin 11:257-262

9. Bittersohl B, Freitas J, Zaps D, Schmitz MR, Bomar JD, Muhamad AR et al (2013) EOS imaging of the human pelvis: reliability, validity, and controlled comparison with radiography. J Bone Joint Surg Am 95:e581-e589

10. Humbert L, De Guise JA, Aubert B, Godbout B, Skalli W (2009) $3 \mathrm{D}$ reconstruction of the spine from biplanar $\mathrm{X}$-rays using parametric models based on transversal and longitudinal inferences. Med Eng Phys 31:681-687

11. Chaibi Y, Cresson T, Aubert B, Hausselle J, Neyret P, Hauger O et al (2012) Fast 3D reconstruction of the lower limb using a parametric model and statistical inferences and clinical measurements calculation from biplanar X-rays. Comput Methods Biomech Biomed Engin 15:457-466

12. Quijano S, Serrurier A, Aubert B, Laporte S, Thoreux P, Skalli W (2013) Three-dimensional reconstruction of the lower limb from biplanar calibrated radiographs. Med Eng Phys 35:1703-1712

13. Assi A, Chaibi Y, Presedo A, Dubousset J, Ghanem I, Skalli W (2013) Three-dimensional reconstructions for asymptomatic and cerebral palsy children's lower limbs using a biplanar X-ray system: a feasibility study. Eur J Radiol 82:2359-2364

14. Baudoin A, Skalli W, de Guise JA, Mitton D (2008) Parametric subject-specific model for in vivo 3D reconstruction using biplanar X-rays: application to the upper femoral extremity. Med Biol Eng Comput 46:799-805

15. Laurent CP, Jolivet E, Hodel J, Decq P, Skalli W (2011) New method for 3D reconstruction of the human cranial vault from CT-scan data. Med Eng Phys 33:1270-1275

16. Aubert B, Vergari C, Ilharreborde B, Courvoisier A, Skalli W (2016) 3D reconstruction of rib cage geometry from biplanar radiographs using a statistical parametric model approach. Comput Methods Biomech Biomed Engin: Imaging \& Visualization. doi:10.1080/21681163.2014.913990

17. Sabourin M, Jolivet E, Miladi L, Wicart P, Rampal V, Skalli W (2010) Three-dimensional stereoradiographic modeling of rib cage before and after spinal growing rod procedures in early-onset scoliosis. Clin Biomech 25:284-291 
18. Barbier O, Skalli W, Mainard L, Mainard D (2014) The reliability of the anterior pelvic plane for computer navigated acetabular component placement during total hip arthroplasty: prospective study with the EOS imaging system. Orthop Traumatol Surg Res 100:S287-S291

19. Bendaya S, Lazennec JY, Anglin C, Allena R, Sellam N, Thoumie P et al (2015) Healthy vs. osteoarthritic hips: a comparison of hip, pelvis and femoral parameters and relationships using the EOS system. Clin Biomech 30:195-204

20. Dubousset J, Charpak G, Skalli W, Kalifa G, Lazennec JY (2007) EOS stereo-radiography system: whole-body simultaneous anteroposterior and lateral radiographs with very low radiation dose. Rev Chir Orthop Reparatrice Appar Mot 93:141-143

21. Dubousset J, Charpak G, Skalli W, de Guise J, Kalifa G, Wicart P (2008) Skeletal and spinal imaging with EOS system. Arch Pediatr 15:665-666

22. Duval-Beaupère G, Marty C, Barthel F, Boiseaubert B, Boulay C, Commard MC et al (2002) Sagittal profile of the spine prominent part of the pelvis. Stud Health Technol Inform 88:47-64

23. Legaye J, Duval-Beaupère G (2005) Sagittal plane alignment of the spine and gravity: a radiological and clinical evaluation. Acta Orthop Belg 71:213-220

24. Vialle R, Levassor N, Rillardon L, Templier A, Skalli W, Guigui P (2005) Radiographic analysis of the sagittal alignment and balance of the spine in asymptomatic subjects. J Bone Joint Surg Am 87:260-267

25. Legaye J, Duval-Beaupere G, Hecquet J, Marty C (1998) Pelvic incidence: a fundamental pelvic parameter for three-dimensional regulation of spinal sagittal curves. Eur Spine 7:99-103

26. Wiberg G (1939) Studies on dysplastic acetabula and congenital subluxation of the hip joint. Acta Chir Scand 11(3):257-262

27. Anda S, Svenningsen S, Dale LG, Benum P (1986) The acetabular sector angle of the adult hip determined by computed tomography. Acta Radiol 27(4):443-447

28. Stem ES, O'Connor MI, Kransdorf MJ, Crook J (2006) Computed tomography analysis of acetabular anteversion and abduction. Skeletal Radiol 35:385-389

29. Zilber S, Lazennec JY, Gorin M, Saillant G (2004) Variations of caudal, central, and cranial acetabular anteversion according to the tilt of the pelvis. Surg Radiol Anat 26:462-465

30. Tönnis D (1976) Normal values of the hip joint for the evaluation of X-rays in children and adults. Clin Orthop Relat Res 119:39-47

31. Idelberg K, Frank A (1951) Uber eine neue method zur bestimmung des pfannendachwinkels bei jugendlichen und erwachsesen. Z Orthop 82:257-262
32. Bland MJ, Altman DG (1986) Statistical methods for assessing agreement between two methods of clinical measurement. Lancet 327:307-310

33. International Organization for Standardization (1994) ISO 5725-4: Accuracy (trueness and precision) of measurement methods and results - Part 4: Basic methods for the determination of the trueness of a standard measurement method

34. International Organization for Standardization (1994) ISO 5725-2: Precision of test methods - Determination of repeatability and reproducibility for a standard test method by inter-laboratory tests

35. Tyrakowski M, Wojtera-Tyrakowska D, Siemionow K (2014) Influence of pelvic rotation on pelvic incidence, pelvic tilt, and sacral slope. Spine 39:1276-1283

36. Assi A, Bakouny Z, Saghbini E, Khalil N, Chelala L, Naoum E, et al (2015) Malpositioning of the patient during x-ray acquisition can affect the assessment of sagittal pelvic parameters: evaluation in adults and children. Proceedings of the 25th congress of International Society of Biomechanics. July 12-16, Glasgow (UK)

37. Assi A, Bakouny Z, Saghbini E, Yared F, Bizdikian A, Esber S, et al (2015). Validity and reliability of hip parameters with pelvic axial rotation during X-ray acquisition. Proceedings of the 25th congress of International Society of Biomechanics. July 12-16, Glasgow (UK)

38. Rampal V, Hausselle J, Thoreux P, Wicart P, Skalli W (2013) Threedimensional morphologic study of the child's hip: which parameters are reproducible? Clin Orthop Relat Res 471:1343-1348

39. van Bosse HJ, Lee D, Henderson ER, Sala DA, Feldman DS (2011) Pelvic positioning creates error in CT acetabular measurements. Clin Orthop Relat Res 469:1683-1691

40. Nelitz M, Guenther KP, Gunkel S, Puhl W (1999) Reliability of radiological measurements in the assessment of hip dysplasia in adults. Br J Radiol 72:331-334

41. Tan L, Aktas S, Copuroglu C, Ozcan M, Ture M (2001) Reliability of radiological parameters measured on anteroposterior pelvis radiographs of patients with developmental dysplasia of the hip. Acta Orthop Belg 67:374-379

42. Adamczyk E, Sibiński M, Sobala W, Synder M (2011) The assessment of changes in radiological parameters of acetabulum of the hip joint according to position of the pelvis. Chir Narzadow Ruchu Ortop Pol 76:9-13

43. Weir JP (2005) Quantifying test-retest reliability using the intraclass correlation coefficient and the SEM. J Strength Cond Res 19:231-240

44. Rosskopf AB, Pfirrmann CWA, Buck FM (2016) Assessment of two-dimensional (2D) and three-dimensional (3D) lower limb measurements in adults: comparison of micro-dose and low-dose biplanar radiographs. Eur Radiol. doi:10.1007/s00330-015-4166-5 